\title{
Rethinking extensive green roofs to lessen emphasis on above-ground biomass
}

\author{
Richard K. Sutton ${ }^{1}$ \\ ${ }^{1}$ Professor, University of Nebraska-Lincoln, Lincoln, NE, rsutton1@unl.edu
}

Sutton, R., 2013. Rethinking extensive green roofs to lessen emphasis on above-ground biomass. Journal of Living Architecture. 1(1): 36-38. http://greenroofs.org/resources/JOLA2013Volume1(Issue1)Sutton(2) 


\begin{abstract}
In the future, most green roof applications will not be highly visible, yet these roofs will still provide the benefits of heat island reduction, stormwater control and biodiversity for hard-surfaced cities. However, human bias in wanting more biomass and visible blooms leads green roof horticulturalists and their approach of maximizing those aspects down a slippery slope that, in turn, leads to increased hours of labor, over-watering and fertilizing and specifying too many cultivars.
\end{abstract}

Keywords: green roof, horticulture, biomass, shortgrass prairie

\title{
Ecological Knowledge Meets Horticultural Bias
}

Studied natural environments may offer a broader perspective for the future of green roof ecosystems. For example, while shortgrass prairie researchers have concentrated on dominant shortgrass prairie plant, blue grama (Bouteloua gracilis) in autecological (i.e., ecology of an individual plant and its surrounding) studies, they have also examined the whole ecosystem's seasonal water budget, root turnover rates, organic matter and nutrient cycling, and the microbial trophic levels. At a broader (synecological) level they have studied the species mix, role of exotic annual weeds, seedling establishment and seed bank, root competition, gap phase and disturbances over time and space, and site microstructure that facilitates recruitment (Laurenroth and Burke 2008).

Meanwhile, Horticultural approaches to greening of roofs are mostly autecological, concentrate on a small array of species with heavy emphasis on Sedum sps. and confront limits in media, water and nutrients by manipulating these components through prescription and specification of material blends, irrigation scheduling, and fertilization formulations. Horticulture's bias, like that of range management, focuses on maximizing vegetative growth rates for plant tops, attaining individual plant vigor, and selecting a narrow germplasm base of cultivars, chosen predominantly for flower production. All of these activities require increased labor.

This bias comes by optimizing growing conditions for individual plants therefore, horticultural research has largely not taken a more holistic, synecological approach and examined plant-to-plant interactions, recruitment, soil microbiology, root turnover rates, or matching nutrient inputs and outputs on a green roof's partially closed system. Horticultural research on green roofs has largely been interested in manipulating the individual plant within the system, not in letting that system reach a steady state with minimal inputs.

\section{Ecosystem Thinking}

Unlike the open system of the shortgrass prairie, an extensive green roof is largely self-contained. Ecological studies of shortgrass prairies have detailed its inputs, outputs, growth and change. Inputs include sun, water, $\mathrm{CO}_{2}$ and some nitrogen. Nitrogen and other nutrients however, largely come from recycling organic matter by microorganisms. Atmospheric nitrogen is also fixed by community legumes and arrives through rainwater. The dominant grasses of the shortgrass prairie grow well with minimal nitrogen. Outputs include water, O2 and nitrogen, and biomass. Outputs can be increased if the above-ground biomass is removed each year (i.e., via grazing). In such situations below-ground storage of carbohydrates allow top regrowth. However, without inputs of grazing animal waste, over time, loss of micro-nutrients may become critical. Yet as a contained system an extensive green roof can more easily be monitored for inputs and outputs than a prairie, though no good examples of such comprehensive monitoring appear to have been published. 
Never enough rain falls on a short grass prairie to bring soil organic matter to same level as found in tallgrass prairie. Likewise, low rainfall means less leaching of soil nutrients. Much of the nutrient storage in shortgrass prairie resides in stable pools of soil organic matter closely associated with plant roots. Storage of carbohydrates and moisture occurs within the root system of short-grasses; also these roots largely make use of resources in the top $20 \mathrm{~cm}$ (Sun et al, 1997) of the soil. Because of this, below ground biomass becomes more important than above ground biomass. Minimal growth in such a system conserves macro- and micro-nutrients over time, and binding these nutrients also ensures that nitrophilous weeds are at a competitive disadvantage. It also reduces combustible fine litter and dead standing material. While no studies have been published, observations of native short grass roots shows they appear to have significantly more below-ground biomass than Sedum sps.

\section{Biomass Approach}

Horticultural green roof design often first emphasizes flowers, i.e., an above-ground biomass approach, whose ornament will be wasted, unseen on limited accessibility extensive green roofs potentially covering hundreds of millions of square feet of factory, warehouse, and big box commercial roofs. These roofs however, still offer benefits of heat island amelioration, stormwater attenuation, and increased sites for biodiversity. The primary function of plant selection for green roofs is rooting to hold media in place. The other functions like capturing and slowing of stormwater, summer cooling through transpiration and providing diversity of food and foraging habitat for invertebrates and birds, comes from roots and can be realized in thoughtful initial design.

After an establishment phase of 3-5 years, annual, above-ground biomass production on extensive green roofs should not be an aim. Because the past approaches of horticulture's focus on such biomass production, it misses an important question: Would it be possible to reach homeostasis under a limited water regime where the plants produce enough below ground biomass to survive and maintain their roots with minimal aboveground biomass production? Odum's (1969) exposition of developmental differences between early and mature ecosystems notes among other things large differences at homeostasis. Mature ecosystems (e.g. shortgrass prairie) have developed internal symbioses, allocated energy to maintenance, not growth of biomass, good nutrient conservation, good resilience, low entropy, and high information, just the opposite of simple ecosystems such as those highly visible green roofs dominated by Sedum sps. With the vast majority of roofs not accessible for human interaction, the focus on highly visible biomass limits the functionality of and wider spread implementation of green roofs.

\section{Literature Cited}

Laurenroth, W. K. and I. Burke. 2008. Ecology of The Shortgrass Steppe: A Long-Term Perspective. Oxford University Press, New York.

Odum, E. P. 1969 The strategy of ecosystem development. Science, Vol. 164, No. 3877 (Apr. 18, 1969), pp. 262-270.

Sun, G., D.P. Coffin, and W.K. Laurenroth. 1997. Comparison of root distributions of species in North American grasslands using GIS," Journal of Vegetation Science 8.(4): 587-596. 